\title{
A Medical Student Experience: Adding Value and Emotional Support to Patient Interactions
}

Dale S. DiSalvo.

\section{The Experience}

About the Author: Dale DiSalvo is currently a thirdyear medical student at the Pennsylvania State University College of $\mathrm{Me}$ dicine in Hershey, PA, USA out of a four-year medical school curriculum.
Submission: Dec 22, 2014 Acceptance: Feb 5, 2015 Publication: Feb 22, 2015
Note: Names have been changed.

Calvin was an older gentleman with chronic liver failure and ascites (fluid accumulation within the abdomen, specifically the peritoneal cavity), which recurred frequently despite medical therapy. I first met Calvin in a primary care practice and discussed the possibility of seeing him over the course of the year as part of a longitudinal patient care elective; he was agreeable to this.

A few weeks later, I called to check on Calvin after he had undergone a recent paracentesis. He seemed upset. It was not his first paracentesis; he typically had them done at the gastroenterology (GI) office. This time, however, the GI group was not available and instead he was offered an appointment with a different department at the main hospital. He got a little choked up on the phone, and excused himself.

The next time we met in person I asked about his paracentesis. The physicians at the main hospital were behind schedule, and all of the procedure suites were full. When he was taken for his procedure, he went to a makeshift procedure room with an unpadded table. Calvin typically had over $15 \mathrm{~L}$ of ascites drained per procedure, but they would not remove as much this time. When he asked why, the answer was "That's our policy".

After the procedure was over, his back was sore, and he still had quite a bit of ascites. Over the next two days, he continued to leak ascites from his puncture site. When asked about this, he started to tear up and admitted his fear of infection, ruining his furniture, or running out of bandages. He would rather live with the painful, tense ascites than ever have the procedure done there again.

Communication could have improved this experience for Calvin and it is the key for the attention of many other patients. ${ }^{1}$ For example, a question to discover his preferences may sound like this: "We are running behind schedule. We've set up another room where you could have your paracentesis, but it's not very comfortable. Would you prefer to have your procedure now in that room, or would you rather wait for a regular procedure suite?" This would provide a sense of control. Providing a complete explanation for why they could not completely drain his ascites could have made him more understanding of the situation. For example, it may be important to mention the following: "We are short on nursing staff today, and there is no one to monitor you closely if you need medication after your procedure. Removing all of your fluid would mean you would need medication, so we can't remove it all today. It wouldn't be safe. Would you still like to have your paracentesis today?"

One survey found that patients view communication as the second most important competency of physicians, with diagnosis and treatment being most important. ${ }^{2}$ Improving communication allows us to better identify our patients' concerns. ${ }^{3}$ Furthermore, patient-centered care reduces the use of diagnostic tests. ${ }^{4}$

I was able to go with Calvin to his next paracentesis at the $\mathrm{GI}$ office. We made small talk while he waited. When the time came, as he was being taken back to the procedure room, he brought up his previous poor experience and his eyes started to tear up. I took his hand and reassured him that I knew the provider that was doing his procedure today, and she was wonderful. He looked at me and said, "You're the first person that ever called me at home to see how I did after one of these procedures." He took my hand and continued, "Sometimes I think you're the only one that actually listens."

How much of a difference can medical students make? On the day of Calvin's upsetting paracentesis, a medical student could have explained why things weren't running smoothly, why there were limitations on what they could do for him, and changed his entire experience. We can offer our time. A study of internal medicine interns showed that they spent only $12 \%$ of their time engaged in direct patient care activities. ${ }^{5}$ Medical students have more time than that to spend with the patient. This is a privilege.

In a study involving patients that interacted with first and second year medical students in the ambulatory setting, $43 \%$ of

${ }^{1}$ Medical student, Penn State Hershey College of Medicine, United States. 
patients felt that students added value to their visit. ${ }^{6}$ We can do better than $43 \%$, if we seek those opportunities out. If a preceptor is running behind in clinic and you as a student are seeing patients ahead of the preceptor, take that time to understand that patient's social issues. If things aren't running smoothly on rounds, and a patient seems frustrated, circle back and offer an explanation.

Take advantage of those opportunities, and carry those experiences forward throughout your training. I cannot imagine anyone discouraging a student from talking to a patient. It is my hope that medical students can aid in understanding our patients' concerns and build a more patient-centered healthcare environment.

\section{References}

1. Kolb R. How Can I Help You?: Perspectives from a Patient with a Hearing Loss. Int J Med Students 2013;1(2):94-6.

2. Dimatteo MR. The Role of the Physician in the Emerging Health Care Environment. West J Med. 1998;168(5):328-33.

3. Maguire $P$, Pitceathly $C$. Key communication skills and how to acquire them. BMJ. 2002 Sep;325:697-700.

4. Stewart M, Brown JB, Donner A, McWhinney IR, Oates J, Weston WW, et al. The Impact of Patient-Centered Care on Outcomes. J Fam Pract. 2000;49(9):796-804.

5. Block L, Habicht R, Wu AW, Desai S V, Wang K, Silva KN, et al. In the wake of the 2003 and 2011 duty hours regulations, how do internal medicine interns spend their time? J Gen Intern Med. 2013 Aug;28(8)1042-7.

6. Isaacson JH, Neides D, Mayer M, Nottingham K. Patient perceptions of having 1 st- and 2 nd-year medical students involved in their care. Teach Learn Med. 2014 Jan;26(2):164-7

\section{Acknowledgments}

None.

Conflict of Interest Statement ct Funding

The author has no funding, financial relationships or conflicts of interest to disclose.

Author Contributions

Conception and design the work/idea, Write the manuscript, Critical revision of the manuscript, Approval of the final version: DDS.

Cite as:

DiSalvo DS. A Medical Student Experience: Adding Value and Emotional Support to Patient Interactions. Int J Med Students. 2014 Nov-2015 Mar;3(1):63-4. 